\title{
Developing solutions for pay-as-you-throw information systems
}

\author{
J.P. Barraca, L.P. Almeida, A. Santos, H. Moreira, Ó. Pereira, R. Luís Aguiar \\ University of Aveiro, Telecommunications Institute, 3810-193 Aveiro, Portugal \\ C. Dias-Ferreira \\ Universidade Aberta, Lisboa, Portugal \\ Research Center for Natural Resources, Environment and Society (CERNAS), Polytechnic Institute of \\ Coimbra, Portugal
}

\begin{abstract}
The development of pay-as-you-throw (PAYT) systems - one of the strategies behind smart waste concepts - has a large set of challenges from the information technology (IT) point of view. The diversity of existing charging models in different towns already poses a complexity problem for a single universal IT solution. The situation is even more complex as the diversity of pay-as-you-throw systems is very large, with different tariffs and different objectives. This paper describes the development of an information system for supporting multiple approaches for PAYT systems and describes its implementation in the context of a European project. The design strategy and the use of best practices lead to a scalable and effective PAYTspecific Information System that has proved itself able to support a diversity of requirements across south Europe.
\end{abstract}

\section{INTRODUCTION}

The challenges of a sustainable society cover a wealth of aspects, from transportation to energy production, from materials reuse to proper disposal of unavoidable waste. As the world becomes more city-centric, urban centers are becoming megapolis, and population densities reach extreme values, increasing pressures.

Waste management becomes a critical activity in this context. The amount of waste produced in these megapolis is a major hindrance to society sustainability, and strategies for improving the eco-footprint of this waste are essential for our common future. These strategies resort both to less waste - through change of habits of the populations - and to improved recycling ratios which are achieved by improved technologies and (again) by changing population habits. Overall, the targets of the European Commission for 2020 impose a significant reduction of the landfill usage and require the establishment of a consensual circular economy where waste is seen as a resource.

In this context, the strategies associated to pay-as-you-throw (PAYT) waste tariffs are deemed an essential economic instrument in waste management systems, promoting a change of perception on the generation and source-segregation of waste. The PAYT concept is one way to create a more efficient and fairer waste invoice bill calculation. Thus, waste tariffs cease to be collected in the traditional form of a fixed tariff (and/or associated with other factors) and are charged as a variable tariff, which depends on the quantity of waste produced. The advanced separation of waste that is inherently associated to a PAYT system acts as a positive reinforcement loop over the waste producers.

Recently, in Portugal, Greece and Cyprus a novel project (LIFE-PAYT) was launched to assess the deployment (and associated reaction to) of pay-as-you-throw concepts in a diversity of scenarios (Dias-Ferreira et al. 2019). A total of five municipalities were engaged in the process, from large municipalities to small towns: Aveiro, Condeixa-a-Nova, Lisbon, Larnaca and 
Vrilissia. Several waste producers were addressed in this project: big producers (namely industry producing more than $1100 \mathrm{~L} / \mathrm{d}$ ), small businesses (e.g. restaurants), and residential blocks. Different towns were addressing different waste producers, in order to assess the reaction of different populations, and extract knowledge that may facilitate wider adoption in further locations. Given the differences among the target municipalities and waste producers, the technical solution adopted at the five locations were necessarily different. Regardless of these differences, all PAYT systems have the same main three components (Fig. 1): (1) the sensor and devices sub-system (identifying the user or the container); (2) a data network; (3) and the information system (collecting, storing, processing, and making available all information).

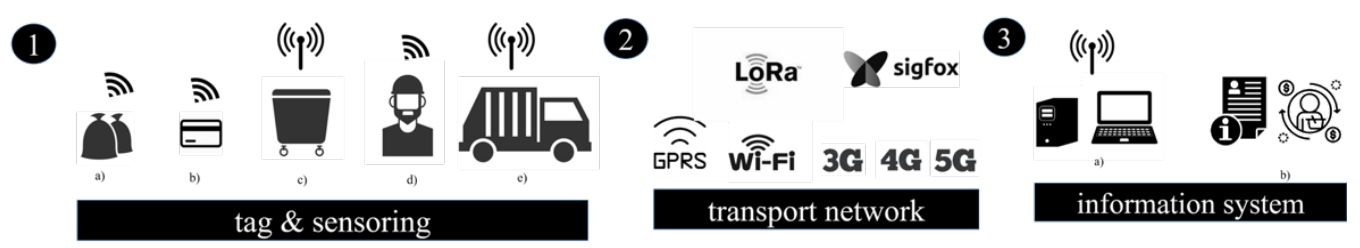

Figure 1. Technology flow for PAYT systems.

The tag \& sensoring (module 1) and the transport network (module 2) have been previously addressed (Madureira \& Dias-Ferreira 2019a, b). The current work describes the development of module 3 , the information system, to be used within the LIFE PAYT project. In this particular case the Information System (IS), named PAYT-IS, is where data from all project sites is collected, processed and made available.

\section{THE DESIGN OF PAYT-IS}

\subsection{Users}

From the point of view of usage, the information system has to consider two major types of users: the end-user, who disposes the waste (citizen, industrial unit or commercial facility) and the waste system manager, which collects and manages the waste (either a town hall official, or a manager in a private waste collection company). Besides these, there is also the system administrator, which overall manages the system (manage users, grants access, manages system alerts, monitors platform usage and external interactions, etc). The administrator functions are focused on IT-specific management aspects, and as such will not be detailed in this paper.

It is obvious, in any waste management system, that the type of producer is an essential design parameter - addressing a professional company (e.g. a restaurant) or a residential neighborhood will lead to a different set of parameters required. Also, the same professional company might have several locations registered under a single contract and the applicable waste tariffs might be different than those of domestic waste producers.

The data that the information system needs to provide for each type of end-user are identified in table 1.

Table 1. Functions associated to the waste producers

\begin{tabular}{lcc}
\hline Functions & Non-domestic & Domestic \\
\hline Access street map with waste disposal points & $\mathrm{x}$ & $\mathrm{x}$ \\
Amount of waste disposed & $\mathrm{X}$ & $\mathrm{X}$ \\
Expenses of the last month (tariff simulation) & $\mathrm{x}$ & $\mathrm{x}$ \\
Historic data on expenses and waste production & $\mathrm{x}$ & $\mathrm{x}$ \\
Information on waste containers under collection contract & $\mathrm{X}$ & \\
Add and manage other installations of the same entity & $\mathrm{x}$ & \\
Compare individual waste production with local averages & $\mathrm{x}$ & $\mathrm{x}$ \\
\hline
\end{tabular}


From the waste system manager, it is important to differentiate between door-to-door vs. collective waste collection. These vary substantially in the technology used to link the waste producer to the amount of waste produced. In door-to-door collection approaches each location has its own container. This means that if the container is properly identified (e.g. by an RFID tag) then the waste within this container can be linked to a specific waste producer. This is called container identification. Oppositely, if the container is collective (used simultaneously by several users) identifying the container will not allow to know who discarded the waste. In this case it is necessary to identify the individual user, generally through by only allowing access to the waste container to identified users (e.g. through a RFID card), and limiting the volume that can disposed per opening. This is called user identification. There is also the possibility of using pre-paid bags, but since the information system is not essential this situation was not considered.

Each collection strategy has its own relevant set of data that the waste system manager needs to retrieve from the information system, as shown in Table 2.

Table 2. Functions associated to the waste management entity

\begin{tabular}{|c|c|c|}
\hline Functions & Door-to-door collection & Collective waste containers \\
\hline Access map with associated containers & $\mathrm{X}$ & $\mathrm{x}$ \\
\hline Generate file with customer list & $\mathrm{x}$ & \\
\hline Generate invoice data & $\mathrm{x}$ & $\mathrm{x}$ \\
\hline Manage user access cards & & $\mathrm{x}$ \\
\hline \multicolumn{3}{|l|}{ Analyse: } \\
\hline - producer with most/less waste production & $\mathrm{x}$ & \\
\hline - producer with most/less separation ratio & $\mathrm{x}$ & \\
\hline - location of installation & $\mathrm{x}$ & \\
\hline - location of containers & & $\mathrm{x}$ \\
\hline \multicolumn{3}{|l|}{ Access information on: } \\
\hline - total expenses per producer & $\mathrm{x}$ & $\mathrm{x}$ \\
\hline - waste production per type & $\mathrm{x}$ & \\
\hline - evolution of waste production & & $\mathrm{x}$ \\
\hline - installation details & $\mathrm{x}$ & \\
\hline - container usage & & $\mathrm{x}$ \\
\hline - producer preferences & & $\mathrm{x}$ \\
\hline
\end{tabular}

\subsection{Technical requisites}

Given the diversity of scenarios that are included in the project, and considering the intended use of the platform in other regions, the system needs to be:

- Scalable: the system may need to scale-up as the number of users, and as the PAYT concept, is gradually deployed in additional towns.

- Easy to deploy and operate: in the future, the system will be deployed by potentially different IT teams, associated to different municipalities, and has to be easy to operate by those (very different) professionals.

- Easy to configure and change: by the different requirements and potentially different evolution paths inside each municipality, PAYT-IS should be easy to change according to the specific requirements of each municipality.

- Easy to interact: PAYT-IS will have to cope with a diversity of users, with different abilities in interacting with IT technologies.

- Privacy-aware: the system should respect all relevant privacy and security requirements, at least matching those related to the European General Protection Data Regulation.

- Future proof: The system should not provide a lock-in solution, binding municipalities in their future IT strategies. 
- Usable in different languages: given the different countries of the municipalities involved (Portugal, Greece, Cyprus), the European context (English) and the replication goals, PAYT$I S$ should be able cover any present as well as future usage, in different countries.

\section{DEVELOPMENT OF PAYT-IS}

The development of the information system was based on several best practices in the area. The architecture of the system developed (Fig. 2) was based in open-source software, relied in RESTfull services (Booth et al. 2004) and REST (Castillo et al. 2011) communications, in a micro-services environment, and using containers (Jaramillo et al. 2016). Some of the opensource components and information systems' best practices used in the architecture are clearly referenced (RabbitMQ, PostgreSQL, CKAN, ELK) in the picture. The system contains the following independent modules deployed according to a highly decoupled micro-services approach.

- Log Module - all interactions with PAYT-IS are recorded by this model, that may then provide a diverse set of reports.

- Authentication Module - This is the module that handles all security aspects of the (different) user credentials, accessing the security levels of the user. In particular, it implements a strict, label based, access control system to all data and resources.

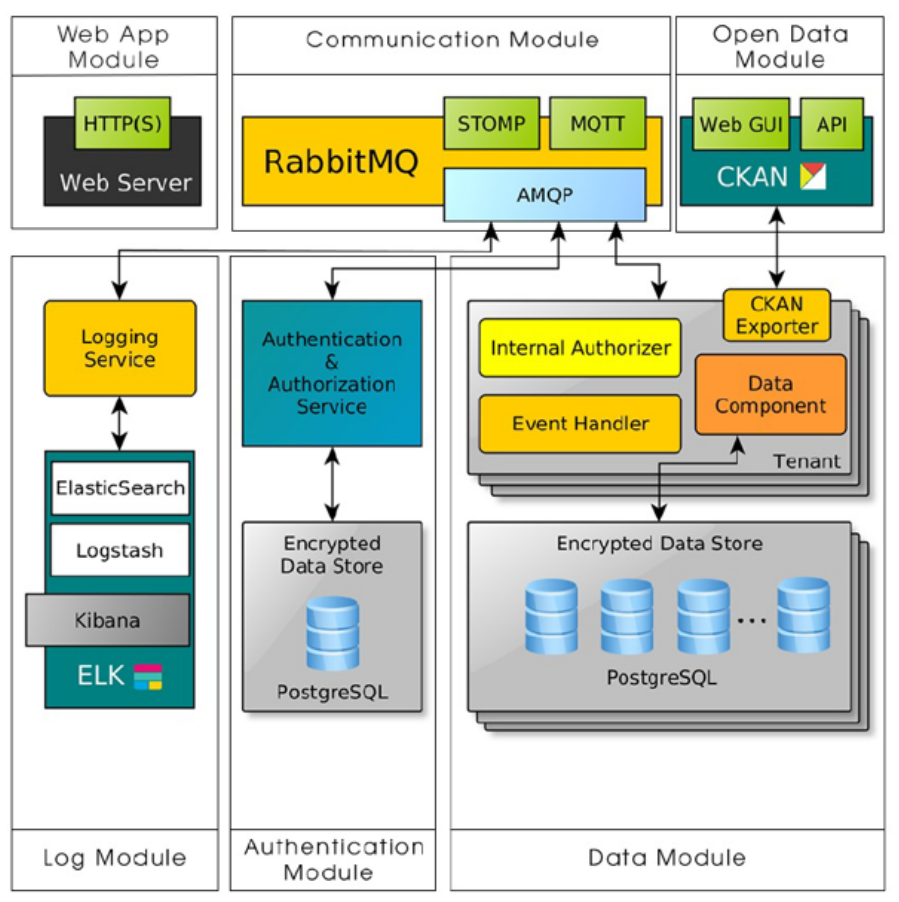

Figure 2. System architecture

- Data Module - This module contains the database(s) where all information is stored. We use scalable contextual approaches (Antunes 2016) to improve future data analysis over the system. The data models for the databases are essential for the scalability and flexibility of $P A Y T-I S$. Also, data is strongly encrypted with municipality specific keys.

- Communication Module - all communication between PAYT-IS modules goes through this module, that manages and brokers the access. The only exception is the Open Data Module, that has a separate external interface, since it may have a separate access control. This module is agnostic to the networking technology, and can be supported even in novel networks for the Internet of Things (e.g. Suarez et al. 2016, Antunes et al. 2015). 
- Open Data Module - due to open data regulations, PAYT-IS contains a module that provides anonymized and summarized reports, that can be used by different entities. These reports may have separated distribution lists.

- Web Server Module - main interaction interface for user(s), both the waste producers, the PAYT administrators, and the waste managers.

One final word is needed for localization aspects. The requirement that the system is to be used in different languages (Portuguese, English and Greek) - some of which not even supporting western alphabet, posed a real requirement in terms of the design of the PAYT-IS. The solution found was resorting to a software pattern, Flux (Facebook 2017), which is based on Stores containing the application data and logic. They also contain the language selected by each active user (session). Changing the language in a view dispatches a change to all stores. Views that are observing those Stores will be promptly updated with the new state. This is also used to disseminate real time information, arriving from sensors, resulting in a responsive and reactive interface.

Overall, this design strategy and these Information System best practices lead to a scalable and effective information system for waste management.

\section{SYSTEM ASSESSMENT}

PAYT-IS is being used inside the LIFE-PAYT project, and fulfilling the requirements for the project. As a matter of illustration of its behaviour, we can show some of the interface screenshots for small and big producers (Fig. 3). Figure 4 illustrates screenshots for the waste managers, in particular the interfaces detailing comparative data for the different types of waste, and the indication of the top ranking waste producers, as well as their variation.
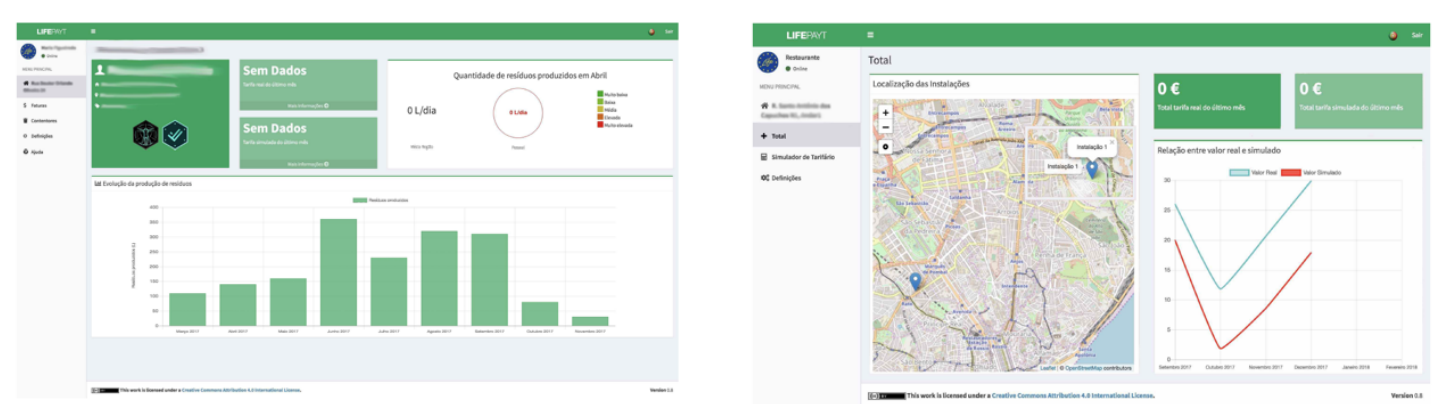

Figure 3. Producer views (left to right): small producer history page; big producer detailed view of "total production".
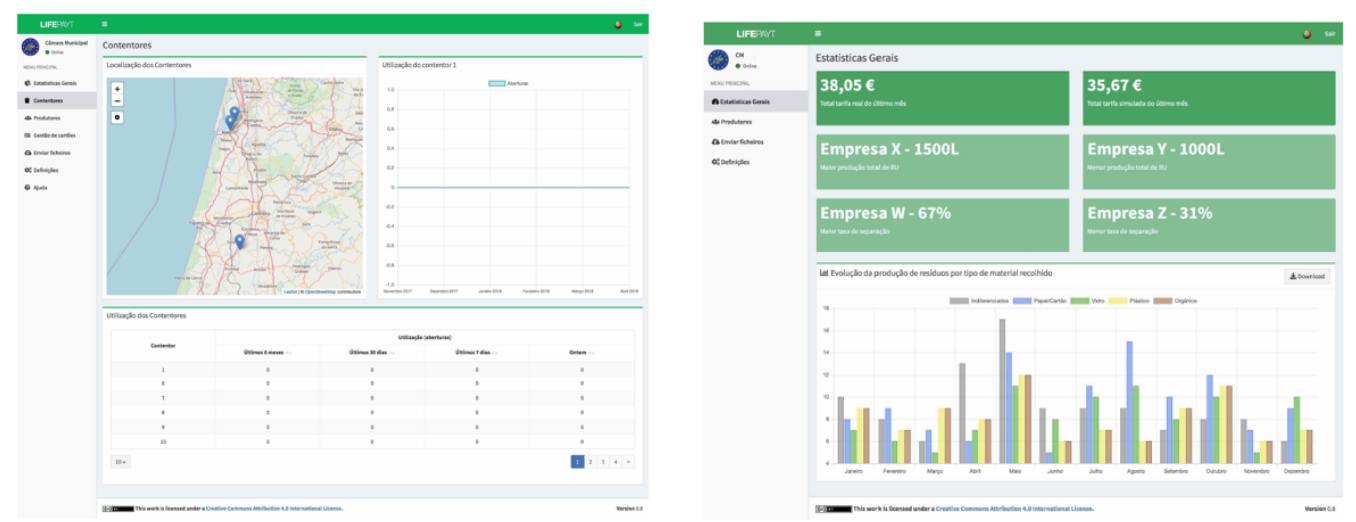

Figure 4. Waste Manager views (left to right): small producers summary; statistics per container 
The system has been tested with real data (input from the different municipalities) and real users (small producers and waste managers). Overall performance has been measured to be within usability limits, with average web page loads inferior to 2 seconds (first page load taking almost 9 sec occasionally, depending on the network bandwidth of the client). After all caches in the browser are updated, the interaction flows with times in the order of the tens of milisseconds for each isolated interaction. Furthermore, a scalability assessment was performed with a simulated municipality with 10,000 users, and a peak 1000 accesses at the same time.

\section{CONCLUSIONS}

PAYT systems are an essential component for transforming the way people look at waste, and develop a more sustainable society. Given the diversity of technical solutions existing, any PAYT system will necessarily need to deal with technology complexity, which will impose the information system to be the clear system integrator for all underlying technology.

We developed an information system (PAYT-IS) that is able to cope with the different implementations of PAYT concept. This system was developed following a set of best practices and resorting to open source software for a future-proof implementation. The resulting system has been deployed to support the real-life scenarios of the LIFE-PAYT project, and satisfactory handled the diversity of PAYT approaches pursued in this project.

\section{ACKNOWLEDGEMENTS}

The authors acknowledge the financial support of LIFE+ (financial instrument of the EU for the environment) for funding the LIFE PAYT project (LIFE 15/ENV/PT/000609).

\section{REFERENCES}

Antunes, M., Gomes, D. \& Aguiar, R.L. 2016. Scalable semantic aware context storage. Future Generation Computer Systems 56: 675-683

Antunes, M., Barraca, J.P., Gomes, D., Oliveira, P. \& Aguiar, R.L. 2015. Smart Cloud of Things: An Evolved IoT Platform for Telco Providers. Journal of Ambient Wireless Communications and Smart Environments (AMBIENTCOM) 1(1): 1-24.

Booth, D., Haas H., McCabe F., Newcomer E., Champion, M., Ferris, C. \& Orchard, D. 2004. Web Services Architecture. W3C [Online] available: http://www.w3.org/TR/ws-arch/.

Castillo, P., Bernier, J., Arenas, M., Merelo, M. \& Garcia-Sanchez, P. 2011. SOAP vs REST: Comparing a master-slave GA implementation. arXiv preprint arXiv:1105.4978.

Dias-Ferreira, C., Neves, A. \& Braña, A. 2019. The setting up of a pilot scale Pay-as-you-throw waste tariff in Aveiro, Portugal. WIT Transactions on Ecology and the Environment 31: 149-157 (DOI: 10.2495/WM180141)

Facebook Inc. 2017. Flux - In Depth Overview [Online] available: https:/facebook.github.io/ flux/docs/in-depth-overview.html (accessed on 28/02/2019).

Jaramillo, D., Nguyen, D.V. \& Smart, R. 2016. Leveraging microservices architecture by using Docker technology. SoutheastCon, IEEE: 1-5.

Madureira, R.C. \& Dias-Ferreira, C. 2019a. Tag \& sensoring solutions overview for smart cities waste management. This issue (accepted).

Madureira, R.C. \& Dias-Ferreira, C. 2019b. Data communication solutions overview for smart cities waste management. This issue (accepted).

Reichenbach, J. 2008. Status and prospects of pay-as-you-throw in Europe - A review of pilot research and implementation studies. Waste Management 28(12): 2809-2814

Suarez, J., Quevedo, J, Vidal, I., Corujo, D., Garcia-Reinoso, J. \& Aguiar, R.L. 2016. A secure IoT management architecture based on Information-Centric Networking. Journal of Network and Computer Applications 63: 190-204. 